\begin{tabular}{|c|l|}
\hline Title & Preparation and characterization of water-soluble jingle bell-shaped silica coated cadmium sulfide nanoparticles \\
\hline Author(s) & I wasaki, Kentaro; Torimoto, Tsukasa; Shibay ama, Tamaki; Takahashi, Heishichiro; Ohtani, Bunsho \\
\hline Citation & $\begin{array}{l}\text { Journal of physical chemistry. B, 108(32), 11946-11952 } \\
\text { https://doi.org/10.1021/p049814i }\end{array}$ \\
\hline Issue Date & 2004 08-12 \\
\hline Doc URL & http://hdl.handle.net/2115/52787 \\
\hline Type & article \\
\hline File Information & jp049814i.pdf \\
\hline
\end{tabular}

Instructions for use 


\title{
Preparation and Characterization of Water-Soluble Jingle-Bell-Shaped Silica-Coated Cadmium Sulfide Nanoparticles
}

\author{
Kentaro Iwasaki, ${ }^{\dagger}$ Tsukasa Torimoto, ${ }^{\dagger,,, \$}$ Tamaki Shibayama," Heishichiro Takahashi," and \\ Bunsho Ohtani $*, \dagger$ \\ Graduate School of Environmental Earth Science, Hokkaido University, Sapporo 060-0810, Japan, \\ Catalysis Research Center, Hokkaido University, Sapporo 001-0021, Japan, Center for Advanced Research of \\ Energy Technology, Hokkaido University, Sapporo 060-8628, Japan, and "Light and Control", PRESTO, \\ Japan Science and Technology Agency (JST), 4-1-8 Honcho, Kawaguchi, Saitama 332-0012, Japan
}

Received: January 14, 2004; In Final Form: June 8, 2004

Treatment of surface silanol groups with hydrophilic compounds enabled silica-coated cadmium sulfide $\left(\mathrm{SiO}_{2} /\right.$ $\mathrm{CdS}$ ) nanoparticles of core-shell morphologies to be dissolved in a water/methanol mixture. Size-selective photoetching of the particles was performed by irradiation with monochromatic light at $458 \mathrm{~nm}$, resulting in a blue shift of its absorption onset because of the decreasing size of the CdS. TEM analyses revealed that the $\mathrm{SiO}_{2}$ shell structure was not shrunken by photoetching and that a void space (ca. $2.3 \mathrm{~nm}$ ) was formed between the $\mathrm{CdS}$ core and the $\mathrm{SiO}_{2}$ shell to give a jingle-bell structure. The emission spectra of photoetched particles showed the development of band-gap emission when cadmium ion $\left(\mathrm{Cd}^{2+}\right)$ was added and the $\mathrm{pH}$ was adjusted to 10 , whereas the same treatment of original particles gave no peaks assigned to band-gap emission, indicating that the $\mathrm{SiO}_{2}$ shell was sufficiently porous for small ionic species such as $\mathrm{Cd}^{2+}$ to penetrate through the shell and that the photoetched $\mathrm{CdS}$ core incorporated in the $\mathrm{SiO}_{2}$ shell had a bare surface to be covered with a cadmium hydroxide layer. With increasing shell thickness, the rate of CdS photoetching was reduced as a result of decrease in the rate of scavenging of the photogenerated electrons in CdS by electron acceptors such as $\mathrm{O}_{2}$ and methyl viologen $\left(\mathrm{MV}^{2+}\right)$ in solution. The structure of the $\mathrm{SiO}_{2}$ layer was varied by surface modification of the CdS with both 3-mercaptopropionic acid (MPA) and 3-mercaptopropyltrimethoxysilane (MPTS) followed by hydrolysis of its trimethoxysilyl group. FT-IR spectra showed that MPA molecules, but not MPTS molecules, attached to the CdS core surface were eliminated by photoetching of the particles, resulting in the formation of windows in the $\mathrm{SiO}_{2}$ shell. The behavior of CdS emission quenching suggested that $\mathrm{MV}^{2+}$ is transported through the windows to the void space inside the $\mathrm{SiO}_{2}$ shell to reach the CdS core.

\section{Introduction}

Encapsulation of metal or semiconductor nanoparticle cores in hollow spheres has attracted much attention ${ }^{1-15}$ because it is an effective means for preventing aggregation of core particles and because the void space between the core and shell is expected to be suitable as a reaction site for novel catalytic reactions and as a nanosized container for molecules. The fabrication has been performed using core-shell structures as precursors in which nanoparticles were made in the hollow structures by the partial removal of core materials by chemical etching or combustion. To utilize these materials as catalysts or containers, it is important to control the transport of target substrates from the bulk solution to the space inside the shell. Several strategies for investigating permeation of chemical species through shell walls have been reported. For example, the diffusion of quinoline across a polymer shell was monitored by the shift of the plasmon peak position of the incorporated gold $(\mathrm{Au})$ core nanoparticles that were sensitive to changes in

* Corresponding address: Prof. Bunsho Ohtani. Catalysis Research Center, Hokkaido University, Sapporo 001-0021, Japan. Phone: +81-11706-9132. Fax: +81-11-706-9133. E-mail: ohtani@cat.hokudai.ac.jp.

Graduate School of Environmental Earth Science, Hokkaido University.

$\doteqdot$ Catalysis Research Center, Hokkaido University.

$\S$ PRESTO.

"Center for Advanced Research of Energy Technology, Hokkaido University. the refractive index of the solution inside the hollow sphere, ${ }^{9}$ and the difference in the permeabilities of methyl viologen $\left(\mathrm{MV}^{2+}\right)$ and iodide ions through the shell wall was measured on the basis of the fluorescence-quenching behavior of fluorescein isothiocyanate incorporated in a hollow silica sphere. ${ }^{13}$ The permeation properties of a porous titania nanoshell were adjusted by tuning $\mathrm{pH}$ and ionic strength of the bulk solution. ${ }^{14}$ Furthermore, it has been reported that the porosity of a carbon and polymer shell of hollow particles was improved by using mesoporous silica as a template in the fabrication of the shell structure. ${ }^{15}$

Recently, we have reported the preparation of a novel coreshell structure of silica $\left(\mathrm{SiO}_{2}\right)$-coated cadmium sulfide $(\mathrm{CdS})$ nanoparticles using a size-selective photoetching technique. ${ }^{16,17}$ The resulting nanoparticles had a void space between the CdS core and the $\mathrm{SiO}_{2}$ shell, like a nanosized "jingle bell"; the size of the void space could be adjusted from 1.4 to $2.4 \mathrm{~nm}$ by selecting the wavelength of monochromatic light from 514 to $458 \mathrm{~nm}$, respectively, used in the size-selective photoetching. In the proposed process of size-selective photoetching, the $\mathrm{CdS}$ core incorporated in the $\mathrm{SiO}_{2}$ shell is corroded by photogenerated holes to liberate cadmium $\left(\mathrm{Cd}^{2+}\right)$ and sulfate ions $\left(\mathrm{SO}_{4}{ }^{2-}\right)$, and photoexcited electrons in $\mathrm{CdS}$ are removed by the reaction with oxygen molecules. Therefore, changes in the shell morphology such as thickness and coverage will cause variations 
in the photoetching behavior of the $\mathrm{CdS}$ core incorporated in the $\mathrm{SiO}_{2}$ shell because the transport of chemical species through the $\mathrm{SiO}_{2}$ shell is modified. Furthermore, it is also expected that the physicochemical properties of the resulting photoetched core-shell particles can be controlled by modifying the structure of the $\mathrm{SiO}_{2}$ shell.

In the present study, we prepared $\mathrm{SiO}_{2}$-coated $\mathrm{CdS}\left(\mathrm{SiO}_{2} /\right.$ $\mathrm{CdS}$ ) nanoparticles dissolved in a water/methanol mixture that had different shell thicknesses or various degrees of coverage of the $\mathrm{SiO}_{2}$ shell on the $\mathrm{CdS}$ core. The size-selective photoetching behavior and photochemical properties of the $\mathrm{CdS}$ cores were found to be dependent on the structure of the $\mathrm{SiO}_{2}$ shell of the $\mathrm{SiO}_{2} / \mathrm{CdS}$ nanoparticles.

\section{Experimental Section}

Materials. Sodium bis(2-ethylhexyl)sulfosuccinate (AOT), 1,1'-dimethyl-4,4'-bipyridinium dichloride (methyl viologen, $\mathrm{MV}^{2+}$ ), 3-mercaptopropyltrimethoxysilane (MPTS), tetraethyl orthosilicate (TEOS), and 3-mercaptopropionic acid (MPA) were purchased from Tokyo Chemical Industry. Cadmium perchlorate was obtained from Kishida Reagents Chemicals. Diethylphosphatoethyltriethoxysilane (PETS) was purchased from Gelest Inc. Other chemicals used in this study were supplied by Wako Pure Chemical Industries. Aqueous solutions were prepared just before use with water purified by a Yamato/Millipore WP501 Milli-Q system.

Preparation of CdS Nanoparticles in Reverse Micelles. $\mathrm{CdS}$ nanoparticles were prepared in reverse micelle solutions by the previously reported procedure with a slight modification. ${ }^{16,17}$ A $240-\mathrm{cm}^{3}$ portion of a heptane solution containing $17 \mathrm{~g}$ of AOT and $6.9 \mathrm{~cm}^{3}$ of water was divided into three solutions, A $\left(100 \mathrm{~cm}^{3}\right), \mathrm{B}\left(100 \mathrm{~cm}^{3}\right)$, and $\mathrm{C}\left(40 \mathrm{~cm}^{3}\right)$. To solutions $\mathrm{A}$ and $\mathrm{C}$ were added 0.67 and $0.26 \mathrm{~cm}^{3}$, respectively, of $1.0 \mathrm{~mol} \mathrm{dm}^{-3} \mathrm{Cd}\left(\mathrm{ClO}_{4}\right)_{2}$ aqueous solution, and $0.67 \mathrm{~cm}^{3}$ of $1.0 \mathrm{~mol} \mathrm{dm}{ }^{-3} \mathrm{Na}_{2} \mathrm{~S}$ aqueous solution was added to solution $\mathrm{B}$. After these solutions had been stirred individually for $1 \mathrm{~h}$, solution A was poured into solution $\mathrm{B}$, and the mixture was stirred vigorously for $15 \mathrm{~min}$, resulting in the formation of a transparent yellow solution of CdS nanoparticles. Solution C was added to the $\mathrm{CdS}$ solution, and the resulting mixture was stirred for another $15 \mathrm{~min}$ to obtain $\mathrm{CdS}$ particles having cadmium-rich surfaces. A yellow solid was obtained by vacuum evaporation of the solvent and was dissolved in $200 \mathrm{~cm}^{3}$ of toluene (solution D).

$\mathrm{SiO}_{2}$-Coated CdS Nanoparticles with Different Shell Thicknesses. Coating of CdS nanoparticles was performed through three steps of layer-by-layer accumulation of (1) anchoring, (2) intermediate, and (3) outermost layers as shown in Scheme 1a. An anchoring layer was prepared by the reaction of surface-excess $\mathrm{Cd}^{2+}$ with a thiol group in MPTS followed by hydrolysis of trimethoxysilyl groups to form a $\mathrm{Si}-\mathrm{O}-\mathrm{Si}$ network as a component of the shell structure as follows: A 0.26-mmol portion of MPTS was added to $50 \mathrm{~cm}^{3}$ of solution $\mathrm{D}$ (containing $0.17 \mathrm{mmol} \mathrm{CdS}$ ), and the mixture was stirred for $1 \mathrm{~h}$. Then, a $17-\mathrm{cm}^{3}$ portion of toluene containing $1.2 \mathrm{~g}$ of AOT and $0.1 \mathrm{~cm}^{3}$ of water was added, and the mixture was refluxed for $2 \mathrm{~h}$, resulting in the formation of $\mathrm{a} \mathrm{SiO}_{2}$ shell layer on a CdS core. The solvent was condensed to ca. $50 \mathrm{~cm}^{3}$ to remove water and methanol liberated by the hydrolysis.

Intermediate layers were accumulated by attachment of TEOS to the surface hydroxyl groups on the $\mathrm{SiO}_{2}$ layer. A typical preparation of an intermediate layer is as follows: A 0.52-mmol portion of TEOS was added to a toluene solution of CdS coated with $\mathrm{SiO}_{2}$, and the mixture was stirred at room temperature for
SCHEME 1: Schematic Illustrations of Preparation of $\mathrm{SiO}_{2}$-Coated CdS Nanoparticles (a) Having Different Shell Thickness $\left(\mathrm{SiO}_{2}(x) / \mathrm{CdS}\right)$ and (b) Having Different Shell Coverages $\left(\mathrm{MPA}^{-\mathrm{SiO}_{2}}(\mathbf{2}) / \mathrm{CdS}\right)$
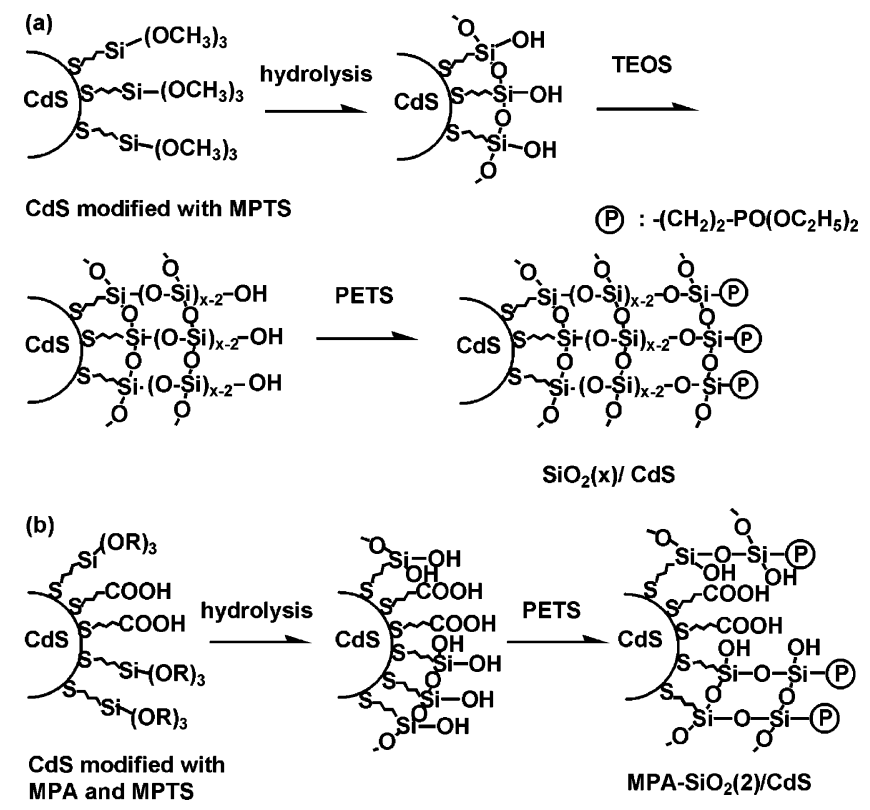

$1 \mathrm{~h}$. After addition of water $(10 \mathrm{mmol})$, the mixture was refluxed for $2 \mathrm{~h}$, and then $5 \mathrm{~cm}^{3}$ of the solvent was removed by evaporation. After the solution had been cooled to room temperature, toluene was added to make the volume $50 \mathrm{~cm}^{3}$. Under the present reaction conditions, $0.26 \mathrm{mmol}$ of TEOS was expected to give a monolayer of $\mathrm{SiO}_{2}$, and the above-described procedure corresponded to the addition of two layers.

The outermost layer, which makes the particle surface hydrophilic, was prepared through the condensation of surface hydroxyl groups with PETS and hydrolysis. PETS $(0.26 \mathrm{mmol})$ was added to a solution of $\mathrm{SiO}_{2}$-coated $\mathrm{CdS}$ and subjected to reflux in the presence of water $(5.2 \mathrm{mmol})$. The thus-obtained $\mathrm{SiO}_{2}$-coated $\mathrm{CdS}$ nanoparticles are denoted in this study as $\mathrm{SiO}_{2}(x) / \mathrm{CdS}$, where $x$ represents the number of $\mathrm{SiO}_{2}$ layers, i.e., anchoring, intermediate, and outermost layers $(x \geq 2)$.

$\mathrm{SiO}_{2}(x) / \mathrm{CdS}$ particles were isolated by the destruction of reverse micelles with addition of methanol, washed with methanol several times, and dissolved in methanol by sonication for several minutes.

CdS Nanoparticles Partially Covered with $\mathrm{SiO}_{2}$. Surface modification with a mixture of MPA and MPTS was performed to prepare $\mathrm{SiO}_{2}$-coated $\mathrm{CdS}$ nanoparticles having different degrees of surface coverage with $\mathrm{SiO}_{2}$ (Scheme 1b). A typical preparation procedure is as follows: MPA $(0.13 \mathrm{mmol})$ was added to $50 \mathrm{~cm}^{3}$ of solution D. After the solution had been stirred for $1 \mathrm{~h}$, MPTS $(0.13 \mathrm{mmol})$ was added, and the mixture was stirred for an additional $1 \mathrm{~h}$. Hydrolysis of the trimethoxysilyl groups of MPTS anchored on CdS was performed by the same procedure as that used for the anchoring layer preparation. Then the outermost layer with PETS was accumulated. The resulting CdS nanoparticles partially covered with a $\mathrm{SiO}_{2}$ shell (MPA-SiO $2(2) / C d S)$ were isolated and purified in a similar way. The molar portion of MPTS among the modifiers, MPTS and MPA in feed, is expressed as $P_{\text {MPTS }}$.

Size-Selective Photoetching of Soluble $\mathrm{SiO}_{2}$-Coated CdS Nanoparticles. An argon ion laser (Ion Laser Technology, model 5500A) and a 400-W mercury arc lamp (Eiko-sha) equipped with optical filters were used as light sources of irradiation at 488 and $458 \mathrm{~nm}$ and at 436 and $404 \mathrm{~nm}$, 


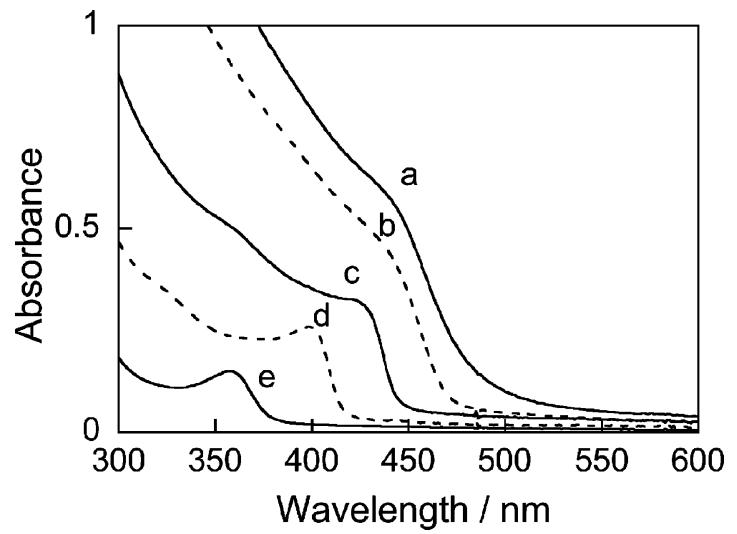

Figure 1. Absorption spectra of $\mathrm{SiO}_{2}(2) / \mathrm{CdS}$ (a) before and after sizeselective photoetching with irradiation at (b) 488, (c) 458, (d) 436, and (e) $404 \mathrm{~nm}$.

respectively. $\mathrm{SiO}_{2}$-coated $\mathrm{CdS}$ particles were dissolved in a water/methanol (9:1) mixture containing $50 \mu \mathrm{mol} \mathrm{dm}{ }^{-3} \mathrm{MV}^{2+}$ and saturated oxygen $\left(\mathrm{O}_{2}\right)$ and then irradiated with monochromatic light until the absorption spectrum of the solution remained almost unchanged. For emission measurements, photoetching was performed by the same procedure but without $\mathrm{MV}^{2+}$, which quenches the emission of CdS nanoparticles, and then the resulting solution was dialyzed with a cellulose membrane against the water/methanol (9:1) mixture for 1 day to remove liberated $\mathrm{Cd}^{2+}$ and $\mathrm{SO}_{4}{ }^{2-}$.

Characterization. Absorption and emission spectra were measured using a photodiode-array spectrophotometer (Agilent Technology 8453A) and a fluorescence spectrometer (Shimadzu RF-5300PC), respectively. FT-IR spectra were recorded on a Shimadzu FT-IR-8200PC spectrometer equipped with a surface reflectance attachment. Specimens for FT-IR measurements were prepared by casting the nanoparticle solution onto gold substrates and drying under vacuum. The structure and size distribution of $\mathrm{SiO}_{2}$-coated $\mathrm{CdS}$ nanoparticles were examined using a JEOL 2010F transmission electron microscope (TEM) with an acceleration voltage of $200 \mathrm{kV}$. The TEM samples were prepared by dropping the nanoparticle solution onto a copper grid with amorphous carbon overlayers (Ouken Shoji, type B) and drying under vacuum.

\section{Results and Discussion}

Size-Selective Photoetching of $\mathrm{SiO}_{2}$-Coated CdS Nanoparticles. It has been reported ${ }^{16,17}$ that destruction of reversed micelles containing $\mathrm{SiO}_{2}(1) / \mathrm{CdS}$, i.e., $\mathrm{CdS}$ covered only with a hydrolyzed MPTS layer, caused coagulation of particles, making them insoluble in any kind of solvent even when the suspension was sonicated for a long time. To prevent this, further surface modification was performed with PETS in this study. The resulting particles did not appear to aggregate during the isolation of particles from the reverse micelle solution, and the particles had hydrophilic surfaces, enabling dissolution in methanol or a water/methanol mixture. Similar surface treatment of the $\mathrm{SiO}_{2}$ shell with various functionalized alkoxysilane compounds has been used to make $\mathrm{SiO}_{2}$-coated nanoparticles, such as $\mathrm{CdSe} / \mathrm{ZnS},{ }^{18} \mathrm{CdTe},{ }^{19}$ and $\mathrm{Au},{ }^{19,20}$ soluble in water.

Figure 1 shows changes in the absorption spectra of $\mathrm{SiO}_{2}(2) /$ $\mathrm{CdS}$ nanoparticles caused by size-selective photoetching with monochromatic irradiation at various wavelengths. The original $\mathrm{SiO}_{2}(2) / \mathrm{CdS}$ nanoparticles gave an exciton peak at around 445 $\mathrm{nm}$ and an absorption onset at $550 \mathrm{~nm}$, indicating that most of the CdS nanoparticles had an energy gap similar to that of the bulk material. Monochromatic light irradiation induced blue (a)

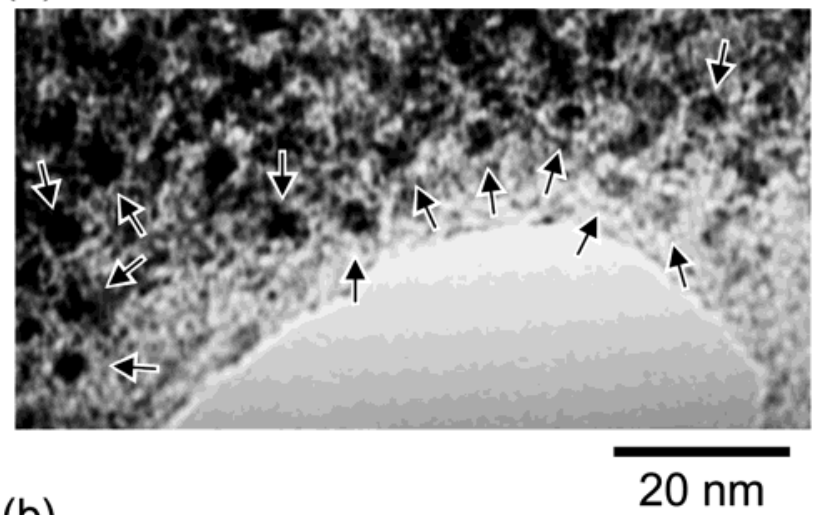

(b)

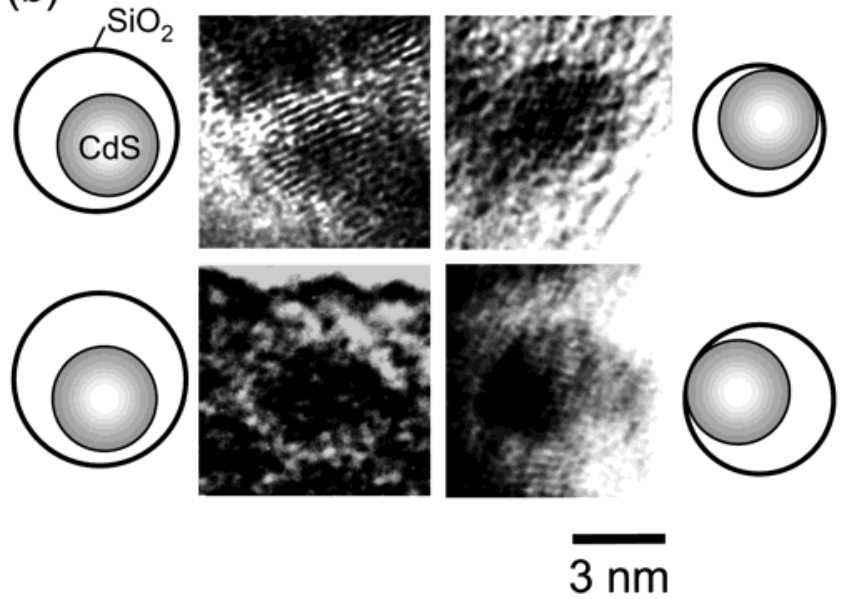

Figure 2. TEM images of $\mathrm{SiO}_{2}(2) / \mathrm{CdS}$ photoetched with irradiation at $458 \mathrm{~nm}$. (a) A typical image in a large area and (b) images with high magnification of individual particles. The schematic illustration of each particle is also shown beside the corresponding TEM image of b.

shifts of the spectra, and exciton peaks became distinct with decreasing wavelength of irradiation. Furthermore, the wavelength of absorption onset of each spectrum agreed well with that of irradiation. It is well-known that CdS nanoparticles are photocorroded to smaller particles according to eq 1 in the presence of dissolved oxygen and $\mathrm{MV}^{2+}$, with $\mathrm{MV}^{2+}$ acting as an electron relay from CdS nanoparticles to oxygen molecules and enhancing the photoetching of $\mathrm{CdS} .{ }^{21,22}$

$$
\mathrm{CdS}+2 \mathrm{O}_{2} \stackrel{h v}{\longrightarrow} \mathrm{Cd}^{2+}+\mathrm{SO}_{4}^{2-}
$$

The results indicate that size-selective photoetching of $\mathrm{CdS}$ cores was successfully performed and the surrounding $\mathrm{SiO}_{2}$ shells prevented the coalescence between the photoetched CdS cores during the process (Scheme 2a), as reported in our previous papers. ${ }^{16,17} \mathrm{CdS}$ nanoparticles were photocorroded until the irradiated light could not be absorbed by the CdS nanoparticles as a result of an increase in the energy gap with decrease in particle size, i.e., size quantization effect. With irradiation of monochromatic light at 488, 458, 436, and $404 \mathrm{~nm}$, exciton peaks appeared at 448, 430, 412, and $364 \mathrm{~nm}$, respectively. The diameters of the photoetched CdS nanoparticles were estimated to be $3.0,2.6,2.3$, and $1.8 \mathrm{~nm}$, respectively, by fitting the experimental results to a theoretical relation between the energy gap and the particle diameter of $\mathrm{CdS} .{ }^{23}$

Figure 2 shows typical TEM images of $\mathrm{SiO}_{2}(2) / \mathrm{CdS}$ photoetched at $458 \mathrm{~nm}$. It can be seen in Figure $2 \mathrm{a}$ that the photoetched CdS nanoparticles, which could be seen as black 


\section{SCHEME 2: Schematic Illustrations of Structural Changes in $\mathrm{SiO}_{2}$-Coated CdS Nanoparticles by Size-Selective Photoetching: (a) $\mathrm{SiO}_{2}(2) / \mathrm{CdS}$ and (b) MPA-SiO 2 (2)/CdS.}

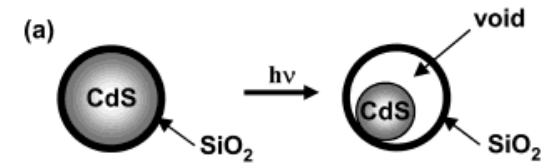

(b)

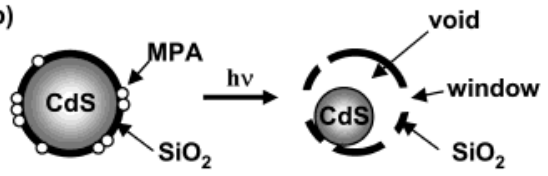

spots, were small and monodispersed, and almost no large particles having the size of original CdS $(4-7 \mathrm{~nm})$ were observed. Furthermore, CdS particles seemed to be incorporated in the hollow $\mathrm{SiO}_{2}$ shells, and void spaces were formed between the CdS particles and $\mathrm{SiO}_{2}$ shells as indicated by the arrows. The electron diffraction patterns of these particles before and after monochromatic irradiation consisted of five clear diffraction rings corresponding to interplanar spacings of $0.34,0.21$, $0.18,0.15$, and $0.11 \mathrm{~nm}$, which were assignable to diffractions from the (111), (220), (311), (400), and (422) planes, respectively, of the cubic structure of CdS. ${ }^{24}$ Figure $2 \mathrm{~b}$ shows typical high-magnification images of $\mathrm{SiO}_{2}(2) / \mathrm{CdS}$. CdS nanoparticles are clearly recognized as a part of the lattice fringe. The fringe corresponds to the interplanar spacing of $0.33 \mathrm{~nm}$ assigned to the (111) lattice plane of the cubic crystal structure. In our previous study, TEM analyses revealed that the application of size-selective photoetching to $\mathrm{SiO}_{2}$-coated $\mathrm{CdS}$ nanoparticles made a jingle-bell structure on a nanometer scale. ${ }^{16}$ Although clear images were difficult to obtain because of the increased thickness of the $\mathrm{SiO}_{2}$ shell in $\mathrm{SiO}_{2}(2) / \mathrm{CdS}$ compared with that of our previous study $\left(\mathrm{SiO}_{2}(1) / \mathrm{CdS}\right),{ }^{16}$ the formation of a similar structure by irradiation was strongly suggested in this study by the high-magnification images in Figure 2b; the photoetched CdS particle is surrounded by a $\mathrm{SiO}_{2}$ shell, and a void space forms between $\mathrm{CdS}$ and $\mathrm{SiO}_{2}$, as depicted in schematic illustrations in Figure 2b. This structure is quite different from that of the original particles: $\mathrm{SiO}_{2} / \mathrm{CdS}$ before photoetching had almost no void space inside the shell (not shown).

The size distributions of CdS core particles before and after the size-selective photoetching were measured by TEM. The original CdS nanoparticles had a broad size distribution with an average diameter $\left(d_{\mathrm{av}}\right)$ of $4.9 \mathrm{~nm}$ and standard deviation $(\sigma)$ of $0.6 \mathrm{~nm}$, whereas irradiation at $458 \mathrm{~nm}$ resulted in a decrease in size, giving $d_{\mathrm{av}}=2.7 \mathrm{~nm}$ and $\sigma=0.3 \mathrm{~nm}$. On the other hand, the $\mathrm{SiO}_{2}$ shell obtained after irradiation at $458 \mathrm{~nm}$ exhibited a relatively wide distribution with $d_{\mathrm{av}}=5.0 \mathrm{~nm}$ and $\sigma=0.8 \mathrm{~nm}$, which are very similar to those of original $\mathrm{CdS}$ nanoparticles, working as a template of the $\mathrm{SiO}_{2}$ shell. These facts show that the $\mathrm{SiO}_{2}$ shell structure remained unchanged with size-selective photoetching without any shrinkage. The size of the void space was calculated as the difference between the average size of the photoetched $\mathrm{CdS}$ cores and that of the $\mathrm{SiO}_{2}$ shells to be $2.3 \mathrm{~nm}$.

Figure 3 shows the emission spectra of $\mathrm{SiO}_{2}(2) / \mathrm{CdS}$ before and after photoetching at $458 \mathrm{~nm}$. At pH 7.0, only a weak broad emission was observed for both particles in the range of wavelengths from 500 to $800 \mathrm{~nm}$ with a peak around $650 \mathrm{~nm}$, which were attributed to the recombination of photogenerated charge carriers at the surface defect sites in CdS nanoparticles. ${ }^{26,27}$ The emission intensity was enhanced ca. 5 times by the photoetching, probably as a result of removal of the

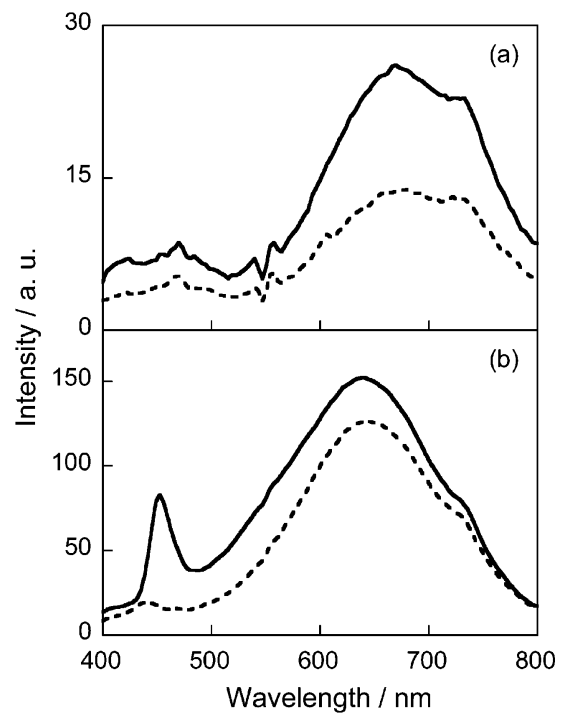

Figure 3. Emission spectra of $\mathrm{SiO}_{2}(2) / \mathrm{CdS}$ (a) before and (b) after size-selective photoetching with irradiation at $458 \mathrm{~nm}$. The spectra were measured in an aqueous solution at $\mathrm{pH} 7.0$ (dotted lines) or in a 1.0 $\times 10^{-4} \mathrm{~mol} \mathrm{dm}^{-3} \mathrm{Cd}\left(\mathrm{ClO}_{4}\right)_{2}$ aqueous solution at $\mathrm{pH} 10$ (solid lines). The excitation wavelength was $300 \mathrm{~nm}$.

radiationless recombination sites in original CdS particles. Similar enhancement of emission induced by size-selective photoetching was observed for $\mathrm{CdS}$ nanoparticles without $\mathrm{SiO}_{2}$ shells in our previous study. ${ }^{25}$ Although addition of $\mathrm{Cd}^{2+}$ at pH 7.0 caused almost no changes in emission, adjustment of the $\mathrm{pH}$ to 10 in the presence of additional $\mathrm{Cd}^{2+}$ in the solution increased the emission intensity in both particles. Furthermore, a sharp emission peak at $460 \mathrm{~nm}$, assigned to band-gap emission, appeared only from the photoetched sample. Henglein et al. reported that addition of $\mathrm{Cd}^{2+}$ to $\mathrm{CdS}$ colloid in an alkaline solution induced the appearance of band-gap emission along with the enhancement of emission from surface defective sites. ${ }^{27}$ They attributed this behavior to blocking of the radiationless recombination sites by a cadmium hydroxide $\left(\mathrm{Cd}(\mathrm{OH})_{2}\right)$ layer. These facts indicate that the bare surface of a CdS core particle exposed by photoetching was covered with a $\mathrm{Cd}(\mathrm{OH})_{2}$ layer, resulting in the appearance of band-gap emission, whereas the surface of the CdS core in the original $\mathrm{SiO}_{2}(2) / \mathrm{CdS}$ was protected by MPTS against the formation of a $\mathrm{Cd}(\mathrm{OH})_{2}$ layer. It should be noted that such photochemical properties of $\mathrm{CdS}$ are influenced by the composition of the bulk solution, even though the $\mathrm{SiO}_{2}$ shell separates them. This fact indicates that the $\mathrm{SiO}_{2}$ shell surrounding the $\mathrm{CdS}$ core is sufficiently porous for small ionic species such as $\mathrm{Cd}^{2+}$ and $\mathrm{OH}^{-}$to penetrate from the bulk solution to the interior of the $\mathrm{SiO}_{2}$ shell.

Dependence of the Rate of CdS Photoetching on the $\mathrm{SiO}_{2}$ Shell Thickness. Irradiation of 458-nm light onto $\mathrm{SiO}_{2}$-coated $\mathrm{CdS}$ nanoparticles having different shell thicknesses induced blue shifts of the absorption spectra of CdS nanoparticles and finally gave an absorption onset at $460 \mathrm{~nm}$ and an exciton peak at $430 \mathrm{~nm}$, irrespective of the shell thickness. These results indicate that the size of the photoetched $\mathrm{CdS}$ nanoparticles was simply determined by the wavelength of the irradiated light used in size-selective photoetching. However, the rate of $\mathrm{CdS}$ photoetching was considerably influenced by the $\mathrm{SiO}_{2}$ shell thicknesses. Representative time-course curves are shown in Figure 4a; the change in the absorbance at $458 \mathrm{~nm}$ of $\mathrm{SiO}_{2}(x) /$ CdS nanoparticles with $x=12$ was slower than that with $x=$ 2. Assuming that the absorption coefficient at $458 \mathrm{~nm}$ was the same as that of original CdS nanoparticles in the early stage of irradiation, the initial photoetching rate $\left(R_{\mathrm{p}}\right)$ of CdS was 

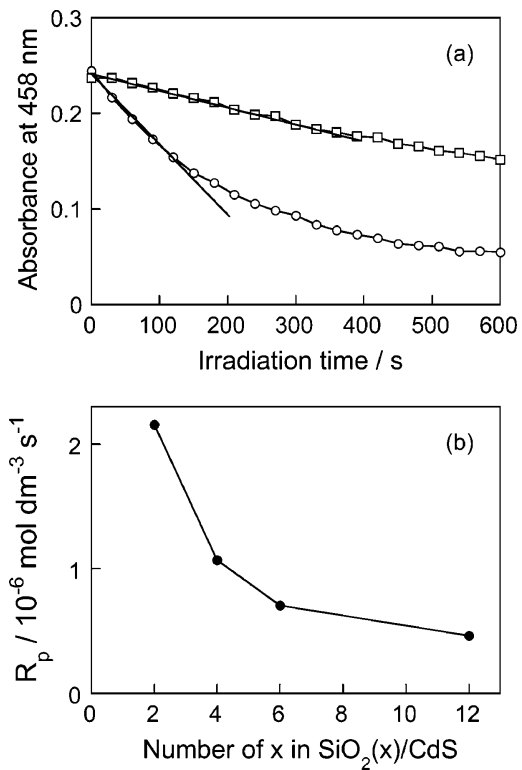

Figure 4. (a) Changes in absorbance at $458 \mathrm{~nm}$ for $\mathrm{SiO}_{2}(x) / \mathrm{CdS}$ by irradiation at $458 \mathrm{~nm}: x=2$ (open circles) and 12 (open squares). Irradiation intensity was $0.24 \mathrm{~mW} \mathrm{~cm}^{-2}$. Straight lines show the gradient of absorbance change at the early stage of irradiation time. (b) Relationship between the initial rate of photocorrosion $\left(R_{\mathrm{p}}\right)$ and the $\mathrm{SiO}_{2}$ shell thickness. The initial concentration of $\mathrm{CdS}$ was $0.64 \mathrm{mmol}$ $\mathrm{dm}^{-3}$.

evaluated from the slope of a linear part of the relation curve between absorbance and irradiation time. As shown in Figure $4 \mathrm{~b}$, it is clear that an increase in the value of $x$ in $\mathrm{SiO}_{2}(x) / \mathrm{CdS}$ induced a remarkable decrease in $R_{\mathrm{p}}$. Because the photocorrosion of $\mathrm{CdS}$ with photogenerated holes requires scavenging of photoexcited electrons by electron acceptors, such as $\mathrm{O}_{2}$ and/ or $\mathrm{MV}^{2+}$ supplied from the bulk solution, the results shown in Figure $4 \mathrm{~b}$ suggest that the reduction of $\mathrm{O}_{2}$ and/or $\mathrm{MV}^{2+}$ by photoexcited electrons in $\mathrm{CdS}$ is greatly retarded with an increase in the $\mathrm{SiO}_{2}$ shell thickness, as a result of the lowered probability of tunneling of the photogenerated electrons through the $\mathrm{SiO}_{2}$ shell and/or the decrease in the rate of $\mathrm{O}_{2}$ or $\mathrm{MV}^{2+}$ penetration through the $\mathrm{SiO}_{2}$ shell wall.

Influence of the $\mathrm{SiO}_{2}$ Shell Coverage on Size-Selective Photoetching. Figure 5 shows FT-IR spectra of various kinds of CdS nanoparticles used in this study. A broad absorption band around $3300 \mathrm{~cm}^{-1}$ and an absorption band at $2900 \mathrm{~cm}^{-1}$ were assigned to $\mathrm{O}-\mathrm{H}$ vibrations of the absorbed $\mathrm{H}_{2} \mathrm{O}$ and $\mathrm{C}-\mathrm{H}$ vibration in the alkyl chain of the surface modifiers, respectively. An absorption band due to $\mathrm{S}-\mathrm{H}$ vibration, ${ }^{28}$ observed at 2560 $\mathrm{cm}^{-1}$ for pure MPTS and MPA, was absent in all cases, indicating that thiol groups of MPTS and MPA were bound to surface $\mathrm{Cd}^{2+}$ sites through $\mathrm{Cd}-\mathrm{SR}$ bond formation. The original particles of $\mathrm{SiO}_{2}(2) / \mathrm{CdS}$ and $\mathrm{MPA}-\mathrm{SiO}_{2}(2) / \mathrm{CdS}\left(P_{\mathrm{MPTS}}=0.5\right)$ showed a broad absorption band due to $\mathrm{Si}-\mathrm{O}-\mathrm{Si}$ vibrations ${ }^{28,29}$ appearing at $1000-1100 \mathrm{~cm}^{-1}$, whereas a sharp absorption band at $1550 \mathrm{~cm}^{-1}$ was observed in the case of MPA-modified CdS and MPA-SiO $2(2) / C d S$ and was assigned to vibration of the carboxylate anion in MPA. ${ }^{28}$ These results revealed that the hydrolysis of MPTS and PETS gave a $\mathrm{Si}-\mathrm{O}-\mathrm{Si}$ network as a component of the $\mathrm{SiO}_{2}$ shell structure in $\mathrm{SiO}_{2}(2) / \mathrm{CdS}$ and MPA$\mathrm{SiO}_{2}(2) / \mathrm{CdS}$, and for MPA-SiO $2(2) / \mathrm{CdS}$, moreover, a part of the CdS surface was also modified with MPA as illustrated in Scheme $1 b$, although the precise coverage by MPA cannot be determined at present.

Size-selective photoetching of $\mathrm{MPA}_{-} \mathrm{SiO}_{2}(2) / \mathrm{CdS}\left(P_{\mathrm{MPTS}}=\right.$ $0.5)$ was successfully performed, and its absorption spectrum

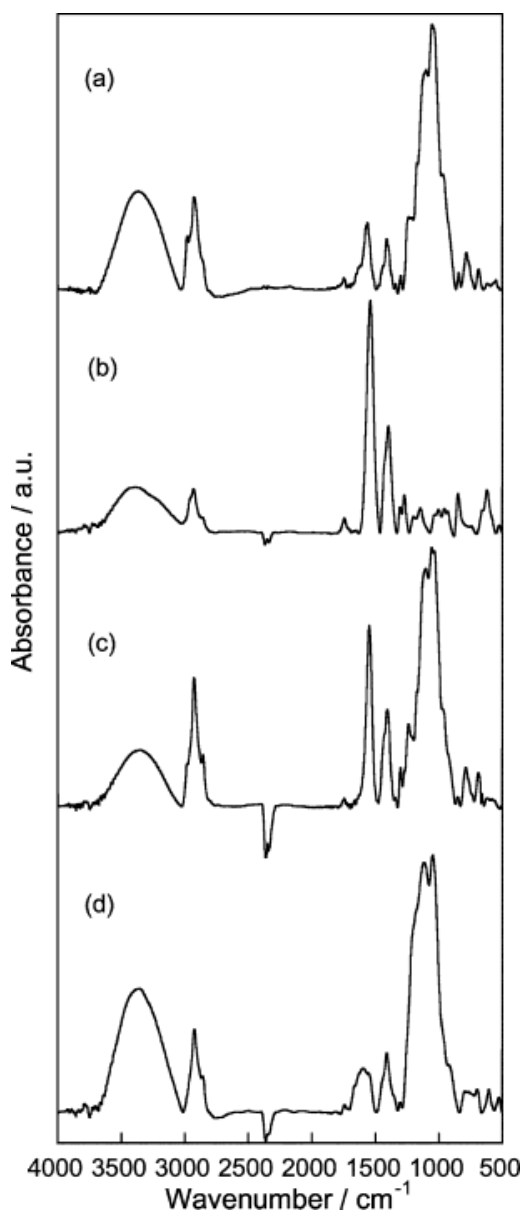

Figure 5. FT-IR spectra of CdS nanoparticles coated with $\mathrm{SiO}_{2}$ and those modified with MPA. (a) Original particles of $\mathrm{SiO}_{2}(2) / \mathrm{CdS}$, (b) MPA-modified CdS, (c) MPA-SiO 2 (2)/CdS with $P_{\text {MPTS }}=0.5$, (d) MPA$\mathrm{SiO}_{2}(2) / \mathrm{CdS}$ with $P_{\text {MPTS }}=0.5$ photoetched at $458 \mathrm{~nm}$.

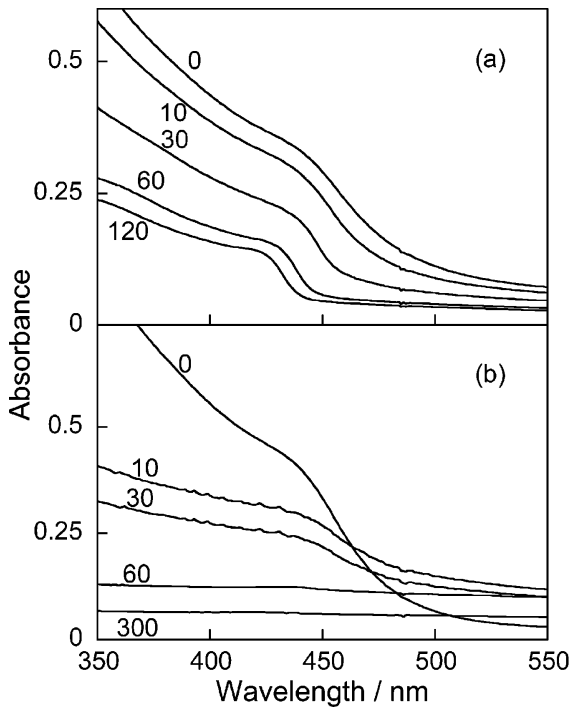

Figure 6. Changes in absorption spectra of $\mathrm{MPA}-\mathrm{SiO}_{2}(2) / \mathrm{CdS}$ during size-selective photoetching with irradiation at $458 \mathrm{~nm}: P_{\text {MPTS }}=$ (a) 0.5 and (b) 0.25 . Irradiation time in the unit of minutes is indicated in the figures. The initial concentration of CdS was $0.64 \mathrm{mmol} \mathrm{dm}^{-3}$.

was blue-shifted (Figure 6a). The irradiation also induced remarkable changes in FT-IR spectra as shown in Figure 5d; the absorption band at $1550 \mathrm{~cm}^{-1}$ due to the carboxylate anion almost disappeared, whereas that at $1000-1100 \mathrm{~cm}^{-1}$ assigned to the $\mathrm{Si}-\mathrm{O}-\mathrm{Si}$ vibration remained. These results indicate that 


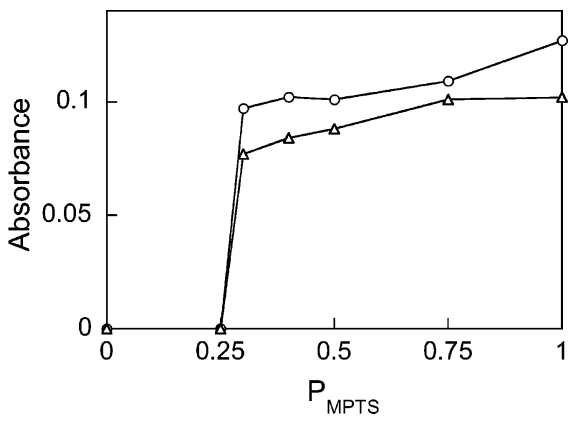

Figure 7. Relationship between $P_{\text {MPTS }}$ and the absorbance of the exciton peak after irradiation at $458 \mathrm{~nm}$ (circles) and at $436 \mathrm{~nm}$ (triangles). The irradiation was performed on the solutions containing $0.64 \mathrm{mmol} \mathrm{dm}^{-3} \mathrm{CdS}$.

MPA bound on the CdS surface was eliminated by the photoetching, possibly as a result of the photooxidation of thiol groups to sulfonate or disulfide groups, but that the $\mathrm{SiO}_{2}$ shell remained unchanged and prevented the coalescence of the photoetched CdS core nanoparticles, i.e., the shell morphology of MPA-SiO $2(2) / C d S$ was modified to have windows in the $\mathrm{SiO}_{2}$ shell as illustrated in Scheme $2 b$.

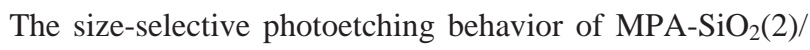
$\mathrm{CdS}$ was greatly dependent on the value of $P_{\text {MPTS }}$ used in the preparation. Figure 6 shows typical changes in absorption spectra of MPA-SiO $\mathrm{M}_{2}(2) / \mathrm{CdS}$ nanoparticles with $P_{\text {MPTS }}$ values of 0.5 and 0.25 during size-selective photoetching with irradiation at $458 \mathrm{~nm}$. The absorption spectrum in the case of $P_{\text {MPTS }}=0.5$ was blue-shifted with irradiation time, and finally the absorption onset agreed with the wavelength of irradiation light as in the case of $\mathrm{SiO}_{2}(2) / \mathrm{CdS}$, whereas almost complete photocorrosion of CdS occurred in the case of $P_{\text {MPTS }}=0.25$ without any blue shift of absorption onset. The absorbance of the exciton peak of CdS core obtained after size-selective photoetching with irradiation at 458 and $436 \mathrm{~nm}$ are plotted in Figure 7 as a function of $P_{\text {MPTS }}$. Similar tendencies were obtained, regardless of the wavelength of irradiation light used for the size-selective photoetching. At $P_{\text {MPTS }} \geq 0.3$, CdS in MPA-SiO ${ }_{2}(2) / \mathrm{CdS}$ was successfully photoetched to the size expected from the wavelength of irradiation light, indicating that the $\mathrm{SiO}_{2}$ shell surrounding the CdS core at higher $P_{\text {MPTS }}$ could prevent coalescence between the photoetched $\mathrm{CdS}$ core particles, although the absorbance of the photoetched particles decreased slightly with decreasing $P_{\text {MPTS }}$. The changes in $P_{\text {MPTS }}$ can vary the size of the windows in the shell of the photoetched particles. However, because the amount of MPA modified on a particle cannot be determined, no information on the size of the windows and their distribution was obtained in the present study. On the other hand, the monochromatic irradiation of $\mathrm{MPA}-\mathrm{SiO}_{2}(2) / \mathrm{CdS}$

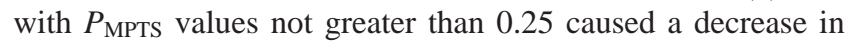
the absorbance of the whole wavelength region in a manner similar to that shown in Figure 6b, and finally, the absorbance of $\mathrm{CdS}$ particles became almost zero, indicating that all $\mathrm{CdS}$ nanoparticles were completely photocorroded. It has been wellknown that the size-quantized semiconductor nanoparticles are unstable and remarkably inclined to coalesce into larger particles because of their large surface-to-volume ratio, resulting in the decrease of the energy gap of the particles, unless stabilizing agents, such as thiol compounds and polyphosphate, are available. ${ }^{30-32}$ Therefore, these facts suggested that the shell at lower $P_{\text {MPTS }}$ was weak enough to be destroyed during photoetching procedures because of its higher porosity and/or that there were large windows to allow free passage of the photoetched cores. Consequently, the photoetched $\mathrm{CdS}$ cores were

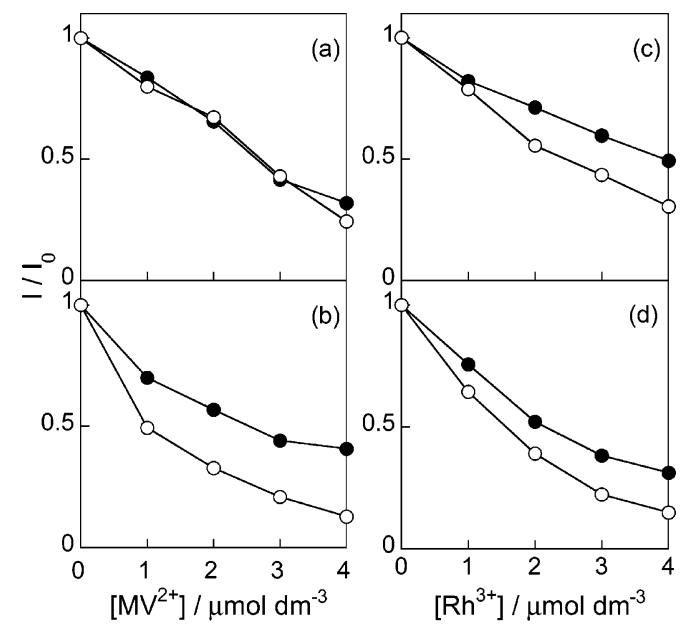

Figure 8. Changes in relative emission intensity $\left(I / I_{0}\right)$ at $650 \mathrm{~nm}$ before (solid circles) and after irradiation at $458 \mathrm{~nm}$ (open circles) as a function of the concentrations of $(\mathrm{a}, \mathrm{b}) \mathrm{MV}^{2+}$ and $(\mathrm{c}, \mathrm{d}) \mathrm{Rh}^{3+}$. The particles used were $(\mathrm{a}, \mathrm{c}) \mathrm{SiO}_{2}(2) / \mathrm{CdS}$ and $(\mathrm{b}, \mathrm{d}) \mathrm{MPA}-\mathrm{SiO}_{2}(2) / \mathrm{CdS}$ with $P_{\mathrm{MPTS}}=0.5$.

not stabilized by the $\mathrm{SiO}_{2}$ shell and coalesced with each other to give larger particles, which could absorb the irradiated photons again because of the decrease of the energy gap and then be subjected to further photocorrosion.

Photochemical Properties of $\mathrm{SiO}_{2}$-Coated CdS Nanoparticles Depending on Shell Coverage. $\mathrm{MPA}-\mathrm{SiO}_{2}(2) / \mathrm{CdS}$ showed only a broad emission around $650 \mathrm{~nm}$, attributed to the recombination of surface defect sites, in an aqueous solution at $\mathrm{pH} 7.0$, irrespective of either $P_{\text {MPTS }}$ or photoetching of the CdS core. Figure 8 shows changes in the relative emission intensity $\left(I / I_{0}\right)$ at $650 \mathrm{~nm}$ of $\mathrm{SiO}_{2}(2) / \mathrm{CdS}$ and $\mathrm{MPA}-\mathrm{SiO}_{2}(2) / \mathrm{CdS}\left(P_{\text {MPTS }}\right.$ $=0.5$ ) before and after size-selective photoetching with irradiation at $458 \mathrm{~nm}$ as a function of the concentration of electron acceptors in the solution. The emission intensity decreased with increasing concentration of electron acceptors of $\mathrm{MV}^{2+}$ or $\mathrm{Rh}^{3+}$, i.e., they acted as quenchers. It is clear that the degree of quenching depends on the kinds of particles and quenchers. The quenching efficiency of original $\mathrm{SiO}_{2}(2) / \mathrm{CdS}$ with $\mathrm{MV}^{2+}$ was almost the same as that of the photoetched sample, whereas the efficiency of $\mathrm{MPA}-\mathrm{SiO}_{2}(2) / \mathrm{CdS}$ was enhanced by the photoetching. The Stern-Volmer plot, a plot of $I_{0} / I$ against the $\mathrm{MV}^{2+}$ concentration, was not linear (not shown), indicating that the quenching rate was not controlled by the collision probability between the $\mathrm{CdS}$ particles and $\mathrm{MV}^{2+}$ molecules. This is similar to previously reported results for $\mathrm{CdS}$ nanoparticles without $\mathrm{SiO}_{2}$ shells showing that $\mathrm{MV}^{2+}$ adsorbed on hexametaphosphatestabilized CdS nanoparticles quenched their emission through a static process. ${ }^{33}$

These results are interpreted by the characteristic shell structure of photoetched MPA-SiO ${ }_{2}(2) / \mathrm{CdS}$ particles; there seem to be windows in the shell wall that are large enough for the transportation of $\mathrm{MV}^{2+}$. The original particles have no void space inside the shell, i.e., the bare surface of CdS is not exposed, and the emission quenching is therefore attributable to the electron transfer to $\mathrm{MV}^{2+}$ adsorbed on the outer shell surface. This is also the case for photoetched $\mathrm{SiO}_{2}(2) / \mathrm{CdS}$ nanoparticles, for which the $\mathrm{SiO}_{2}$ shells have no large windows and $\mathrm{MV}^{2+}$ cannot reach the bare CdS core surface, resulting in the same quenching efficiencies even after photoetching. On the other hand, photoetching of $\mathrm{MPA}-\mathrm{SiO}_{2}(2) / \mathrm{CdS}$ produces a window in the shell along with removal of MPA and the formation of a void space. $\mathrm{MV}^{2+}$ molecules can be adsorbed on the bare $\mathrm{CdS}$ core surface and quench the emission more efficiently compared with $\mathrm{MV}^{2+}$ adsorbed on the outer $\mathrm{SiO}_{2}$ surface. 
The above interpretation is also supported by the emission quenching behavior using $\mathrm{Rh}^{3+}$, which is much smaller than $\mathrm{MV}^{2+}$. For both $\mathrm{SiO}_{2}(2) / \mathrm{CdS}$ and $\mathrm{MPA}-\mathrm{SiO}_{2}(2) / \mathrm{CdS}$, the photoetched particles exhibited larger quenching efficiencies than did the original particles at a fixed concentration of $\mathrm{Rh}^{3+}$, and the degrees of quenching in the presence and absence of shell windows were similar. Because $\mathrm{Rh}^{3+}$ is small, it can penetrate through the shell walls even without windows on them, as seen for $\mathrm{Cd}^{2+}$ going out through the $\mathrm{SiO}_{2}$ shell during the photoetching and $\mathrm{OH}^{-}$reaching the photoetched $\mathrm{CdS}$ surface. Thus, the shell structure did not have a marked influence on emission quenching with $\mathrm{Rh}^{3+}$.

\section{Conclusions}

The effects of the thickness and morphology of $\mathrm{SiO}_{2}$ shells surrounding $\mathrm{CdS}$ nanoparticles on size-selective photoetching behavior and photochemical properties of $\mathrm{CdS}$ nanoparticles were clarified. Size-selective photoetching resulted in exposure of the bare surfaces of the CdS core particles as well as the formation of a void space between the core and the shell. This could not be achieved by conventional preparation methods in which surface modification or incorporation into solid and polymer matrixes has been used for stabilization of sizequantized semiconductor nanoparticles, ${ }^{30-32}$ and the bare surfaces of particles could not be discovered. Because photocatalytic reactions can be driven on the surfaces of semiconductor particles, a $\mathrm{SiO}_{2}$-coated $\mathrm{CdS}$ nanoparticle obtained by size-selective photoetching is a promising material for the investigation of chemical events occurring on the bare surface of a semiconductor nanoparticle. Another interesting finding of this study is that the photochemical properties of photoetched $\mathrm{SiO}_{2}$-coated CdS particles were controlled by the ratio of MPA to MPTS used in the original CdS particles. Photoetching of $\mathrm{CdS}$ induced the elimination of MPA attached to the CdS core, resulting in the formation of windows in the shell through which $\mathrm{MV}^{2+}$ molecules could penetrate inside the $\mathrm{SiO}_{2}$ shell. Control of the window size can enable selective penetration depending on the size of target substrates. Thus, the results presented here should be useful for realization of molecular size-selective photocatalytic reactions that have not been achieved by the conventional semiconductor photocatalysts. Work in this direction is in progress.

Acknowledgment. This research was partially supported by a Grant-in-Aid for Scientific Research (B) (No. 16350095) from the Japan Society for the Promotion of Science.

\section{References and Notes} 6745.

(1) Chang, S. Y.; Liu, L.; Asher, S. A. J. Am. Chem. Soc. 1994, 116 ,
(2) Giersig, M.; Ung, T.; Liz-Marzan, L. M.; Mulvaney, P. Adv. Mater. $1997,9,570$

(3) Giersig, M.; Liz-Marzan, L. M.; Ung, T.; Su, D. S.; Mulvaney, P. Bur. Bunsen-Ges. Phys. Chem. 1997, 101, 1617.

(4) Rodriguez-Gonzalez, B.; Salgueirino-Maceira, V.; Garcia-Santamaria, F.; Liz-Marzan, L. M. Nano Lett. 2002, 2, 471.

(5) Liz-Marzan, L. M.; Mulvaney, P. J. Phys. Chem. B 2003, 107, 7312.

(6) Yin, Y.; Lu, Y.; Gates, B.; Xia, Y. Chem. Mater. 2001, 13, 1146.

(7) Sun, Y. G.; Mayers, B. T.; Xia, Y. N. Nano Lett. 2002, 2, 481.

(8) Sun, Y. G.; Xia, Y. N. Anal. Chem. 2002, 74, 5297.

(9) Kamata, K.; Lu, Y.; Xia, Y. J. Am. Chem. Soc. 2003, 125, 2384. 5652.

(10) Lee, K. T.; Jung, Y. S.; Oh, S. M. J. Am. Chem. Soc. 2003, 125,

(11) Marinakos, S. M.; Novak, J. P.; Brousseau, L. C.; House, A. B.; Edeki, E. M.; Feldhaus, J. C.; Feldheim, D. L. J. Am. Chem. Soc. 1999, $121,8518$.

(12) Marinakos, S. M.; Anderson, M. F.; Ryan, J. A.; Martin, L. D.; Feldheim, D. L. J. Phys. Chem. B 2001, 105, 8872.

(13) Makarova, O. V.; Ostafin, A. E.; Miyoshi, H.; Norris, J. R.; Meisel, D. J. Phys. Chem. B 1999, 103, 9080.

(14) Koktysh, D. S.; Liang, X. R.; Yun, B. G.; Pastoriza-Santos, I.; Matts, R. L.; Giersig, M.; Serra-Rodriguez, C.; Liz-Marzan, L. M.; Kotov, N. A. Adv. Funct. Mater. 2002, 12, 255.

(15) Kim, M.; Sohn, K.; Na, H. B.; Hyeon, T. Nano Lett. 2002, 2, 1383.

(16) Torimoto, T.; Reyes, J. P.; Iwasaki, K.; Pal, B.; Shibayama, T.; Sugawara, K.; Takahashi, H.; Ohtani, B. J. Am. Chem. Soc. 2003, 125, 316.

(17) Torimoto, T.; Reyes, J. P.; Murakami, S.; Pal, B.; Ohtani, B. J. Photochem. Photobiol. A: Chem. 2003, 160, 69.

(18) Gerion, D.; Pinaud, F.; Williams, S. C.; Parak, W. J.; Zanchet, D.; Weiss, S.; Alivisatos, A. P. J. Phys. Chem. B 2001, 105, 8861.

(19) Schroedter, A.; Weller, H.; Eritja, R.; Ford, W. E.; Wessels, J. M. Nano Lett. 2002, 2, 1363.

(20) Schroedter, A.; Weller, H. Angew. Chem., Int. Ed. 2002, 41, 3218.

(21) Matsumoto, H.; Sakata, T.; Mori, H.; Yoneyama, H. J. Phys. Chem. 1996, 100,13781

(22) Torimoto, T.; Kontani, H.; Shibutani, Y.; Kuwabata, S.; Sakata, T.; Mori, H.; Yoneyama, H. J. Phys. Chem. B 2001, 105, 6838.

(23) Nosaka, Y. J. Phys. Chem. 1991, 95, 5054.

(24) Powder Diffraction File; JCPDS International Center for Diffraction Data: Swarthmore, PA, 1982; No. 10-454.

(25) Torimoto, T.; Nishiyama, H.; Sakata, T.; Mori, H.; Yoneyama, H. J. Electrochem. Soc. 1998, 145, 1964.

(26) Resch, U.; Eychmuller, A.; Hasse, M.; Weller, H. Langmuir 1992, $8,2215$.

(27) Spanhel, L.; Hasse, H.; Weller, H.; Henglein, A. J. Am. Chem. Soc. 1987, 109, 5649 .

(28) Socrates, G. Infrared Characteristic Group Frequencies; John Wiley \& Sons: New York, 1980.

(29) Buning, P. A.; Humbel, B. M.; Philipse, A. P.; Verkleij, A. J. Langmuir 1997, 13, 3921.

(30) Wang, Y.; Herron, N. J. Phys. Chem. 1991, 95, 525.

(31) Weller, H. Angew. Chem., Int. Ed. Engl. 1993, 32, 41.

(32) Yoneyama, H. Crit. Rev. Solid State Mater Sci. 1993, 18, 69.

(33) Matsumoto, H.; Uchida, H.; Matsunaga, T.; Tanaka, K.; Sakata, T.; Mori, H.; Yoneyama, H. J. Phys. Chem. 1994, 98, 11549. 